Revista da Seção Judiciária do Rio de Janeiro

Auditorium

ARTIGOS

DOI: https://doi.org/10.30749/2177-8337.v23n45p187-203

\title{
VIOLÊNCIA CONTRA A MULHER: UMA ANÁLISE HISTÓRICA E LEGISLATIVA DA SOCIEDADE BRASILEIRA
}

\section{VIOLENCE AGAINST WOMEN: A HISTORICAL AND LEGISLATIVE ANAL YSES OF THE BRAZILIAN SOCIETY}

\author{
Flávia Sanna Leal de Meirelles* \\ Rabib Floriano Antonio**
}

Resumo: O presente artigo se propõe a analisar, de forma breve, a trajetória histórica da violência contra a mulher na legislação penal brasileira. Para tanto, além da pesquisa doutrinária sobre o tema, observou-se o texto legislativo das diversas leis penais que trataram sobre o assunto no Brasil ao longo de sua História. Verificou-se que, sendo uma categoria qualitativamente minoritária, a mulher foi objeto de tratamentos discriminatórios no texto legislativo brasileiro, sendo recente a positivação de seus direitos no texto de lei específica - a Lei Maria da Penha. É certo que a previsão legal não basta para solucionar o problema, sendo necessário que a consciência acerca da igualdade entre homens e mulheres penetre, de uma vez por todas, na cultura de toda a sociedade.

Palavras-chave: História do Brasil. Direito das Mulheres. Violência.

Abstract: This article intends to briefly analyze the historical trajectory of violence against women in Brazilian criminal law. For this, in addition to the doctrinal research on the subject, we observed the legislative text of the various penal laws that dealt with the subject in Brazil throughout its history. It was verified that, being a qualitatively minority category, the woman was subjected to discriminatory treatments in the Brazilian legislative text, being recent the positivation of her rights in the text of specific law - Maria da Penha Law. It is true that legal provision alone is not enough to solve the problem, and it is necessary that awareness of equality between men and women permeates, once and for all, the culture of the whole society.

Keywords: History of Brazil. Women's Rights. Violence.

\footnotetext{
*Doutorado em andamento na linha de Direito Penal pela Universidade do Estado do Rio de Janeiro (UERJ). Mestre na linha de Direito Penal pela Universidade do Estado do Rio de Janeiro. Graduada em Direito pela Universidade Federal do Rio de Janeiro. Atualmente, é Professora de Direito Penal da UniCarioca; Professora de Direito Penal e de Processo Penal da Universidade Cândido Mendes.

** Mestre em História pela UFJF. Graduado em História pelo Centro de Ensino Superior de Valença. Atualmente é professor auxiliar do Centro de Ensino Superior de Valença.
} 


\section{INTRODUÇÃO}

A problemática acerca da violência contra a mulher não é algo historicamente recente. As ideias que pretenderam fixar os elementos que compõem uma natureza feminina - limitando, portanto, o agir das mulheres - datam do século XIX (KEHL, 2016, p. 14). E, mesmo antes disso, as diversas áreas do conhecimento justificavam, cada uma à sua maneira, a superioridade masculina em relação a tudo aquilo que fosse relacionado com o feminino.

Igualmente, a violência contra a mulher não se restringe a um ou outro território, sendo um problema de magnitude global (NICOLITT; ABDALA; SILVA, 2018, p. 23). Tanto é que também não se limita a determinada categoria de vítimas: todas as mulheres estão, em maior ou menor escala, sujeitas a sofrer a incidência violência masculina. Isto independe de qualquer fator como local de origem, religião, vestimentas ou classe social à qual pertença a mulher.

Sendo um problema que desde sempre vitima a todas as mulheres pelo mundo inteiro, esta violência constitui-se temática de suma importância para a pesquisa acadêmica, motivo pelo qual foi feita a escolha deste tema ao presente trabalho. $\mathrm{O}$ artigo pretende analisar brevemente de que forma o assunto foi objeto das legislações brasileiras ao longo da História do país. Tal análise será feita por meio de uma verificação que se inicia em 1500 e se encerra nos movimentos sociais promovidos e facilitados pelos meios digitais característicos da sociedade atual.

\section{PODER DO PATRIARCADO, UM PROBLEMA HISTÓRICO}

Não é de hoje e nem da sociedade brasileira que a violência contra a mulher e sua versão mais aterrorizante, o feminicídio, é um problema. E a violência está associada com a fragilidade da mulher na malha social.

Acredita-se que, nas sociedades pré-históricas (ágrafas) da Europa, a mulher desempenhava um papel relevante na sociedade, ocupando posições administrativas no meio do clã. Na Grécia antiga, base da cultura ocidental moderna, influenciando comportamentos sociais hodiernos, o papel da mulher era inferiorizado pela 
sociedade e legitimado pelo discurso e linhas de pensamentos de formadores de opinião de época, como, por exemplo, Aristóteles. Na sua obra, Politica, apontava a condição inferior da mulher visto que ela não manifestaria plenamente o logos e nem outras características morais da virtude (ARISTOTELES, 2006, p. 30). Pode-se notar nesta obra o singular debate de Sófocles que incide na forma da sociedade ateniense se opor à participação política da polis, seja, nas palavras de Sófocles:

Todos possuem as diferentes partes da alma, mas possuem-nas diferentemente, pois o escravo não possui de forma alguma a faculdade de deliberar, enquanto a mulher a possui, mas sem autoridade plena, e a criança a tem, posto que ainda em formação [...] (ARISTOTELES, 2006, p. 33).

O papel da mulher na sociedade grega não se resumiu à submissão completa. Esparta, por exemplo, é apontada nas obras do próprio Aristóteles como uma polis que garantia certa participação política e social das mulheres no ambiente privado e público. Para Aristóteles, a sociedade espartana tinha como característica o empoderamento econômico das viúvas que herdavam as propriedades e as transmitia ao novo casamento. Por essa análise podemos notar a transmissão da herança também se fazia por costumes matriarcais (TÔRRES, 2001).

Nas sociedades romanas, o papel da mulher na sociedade foi se elevando gradualmente, conforme avançavam as leis civis do Império Romano. Para Jesus Jr., a limitação à cidadania feminina "permaneceu até o período do Baixo Império quando as mulheres ganham certo espaço em âmbito social e jurídico" (JESUS JR., 2011). As mulheres eram tolhidas da participação de certos benefícios da sociedade, como o acesso aos cargos públicos e participação em assembleias. Não poderiam inclusive ser testemunhas. As questões de estupro eram abordadas de forma tangencial na sociedade. Para Canela (2009, p. 5):

O estudioso moderno, porém, defronta-se, reforma perplexa, com uma inexplicável escassez de fontes jurídicas sobre o tema, as quais somente apresentam breves referências sobre o ilícito. Ademais destaca-se que o estupro per vim não apresentou autonomia conceitual no direito Romano. 
Com a crise de Roma e a superação na Europa para um novo modelo socioeconômico, o feudalismo, a situação da mulher no ponto de vista jurídico - que estabelece sua fragilidade e defesa na sociedade - não melhorou. As invasões bárbaras levaram novos conceitos jurídicos e sociais para a cultura romana decadente, e a ascensão da doutrina cristã medieval, que via a mulher como elemento de pecado original, as deixava à mercê de formas físicas e simbólicas de violência.

Na Idade Média, as mulheres foram infamadas em várias esferas. A título de exemplo, pode-se citar o texto de "O Romande la Rose" de Guillaume de Lorris e Jean de Meung, que assim escreveram:

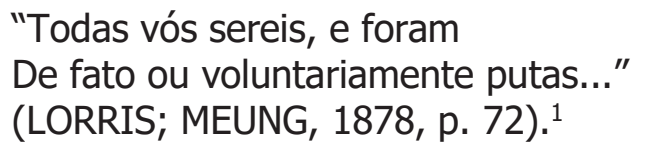

Essa degradação à imagem social e moral da mulher gerou os processos inquisicionais portugueses e espanhóis ao longo da Idade Média e, fundamentalmente, na Idade Moderna. Esse espírito cruzadista contra o mal espiritual-moral que a mulher representava não deixou de ser presente na formação do direito nacional português, que veio a servir de sustentação à cultura jurídica do Brasil colonial e livre.

O primeiro código português, dentro do estudo clássico, é um conjunto jurídico conhecido como Ordenações Afonsinas, que tinha como característica principal transformar a sociedade feudal ibérica em um Estado Nacional Português definitivo. Mas não poderia deixar de lado certas tradições, como a atuação da Igreja e dos valores cristãos medievais em relação à moral da sociedade. Para Flávia Lages de Castro (2007, p. 272-292),

As Ordenações Afonsinas têm muita influência do direito Canônico, muitas vezes, inclusive, tem-se a utilização da palavra 'pecado' como sinônimo da palavra 'crime'. Isso gera, mais que uma simples confusão de termos, uma consequência imediata, não importa

\footnotetext{
${ }^{1}$ O texto original: Toutes estes, serés, ou fustes De fait, ou de volonté, putes; Et qui très-bien vous chercheroit, Toutes putes vous trouveroit. Disponível em: https://www.gutenberg.org/files/16816/16816-pdf.pdf.
} 
somente a materialidade do crime, mas, também, a intenção do acusado [...].

As Ordenações Afonsinas (1446-1521) puniam crimes morais como adultério, feitiçaria, etc. Havia, também, a discriminação pelo critério de gênero, pois a pena imposta por adultério às mulheres era muito mais pesada que ao homem adúltero. $\mathrm{A}$ violência social contra a mulher ibérica passava a ser uma violência legitimada pelas Ordenações.

Os códigos seguintes ${ }^{2}$ também não superaram a característica incorporada ao código afonsino. Nas Ordenações Manuelinas (1521-1602), os fidalgos ainda detinham as vantagens sociais e penais, sendo favorecidos pela lei. Alguns delitos expunham a mulher à violência física e ao assassinato. Na lei manuelina, a mulher adúltera e seu amante poderiam ser mortos pelo marido (com a ajuda de um companheiro, se este quisesse), mesmo sendo um duplo homicídio, mas caracterizaria o ato como uma "não crime" (CASTRO, 2007, p. 279). Pode-se notar o grau de rejeição ao crime moral do adultério, como pecado, que tornava lícito frente a ele o homicídio.

E sob a égide da conquista espanhola sobre o território português, se fez as Ordenações Filipinas, cuja marca ainda mantinha da cultura androcêntrica. O Livro V das Ordenações tratava das amantes de clérigos, que eram malvistas pela sociedade em geral e pela moral religiosa (UNIVERSIDADE DE COIMBRA, [1998]). Quando culpadas pelos seus crimes, deveriam pagar 2 mil réis e eram degredadas por um ano. Na reincidência, eram açoitadas em praça pública, e, na terceira incidência, eram degredadas perpetuamente para o Brasil. Porém, os frades não poderiam ser punidos, apenas entregues à ordem superior. O título XXV sobrepõe, assim como as legislações anteriores, o homicídio ao adultério:

E toda mulher, que fazer adultério a seu marido, morra por isso. E se ella para fazer o adultério por sua vontade se fôr com alguém de caza de seu marido, ou donde a seu marido tiver, se o marido della querelar, ou a accusar, morra morte natural (PIERANGELLI, 1980, p. 33).

\footnotetext{
${ }^{2}$ Foram três as ordenações portuguesas da Era Moderna, a saber: Ordenações Afonsina, Manuelinas e Filipinas.
} 
Aqui há uma definição clara de como as legislações ibéricas funcionaram como legitimadoras da violência contra a mulher, ora ajudando na conformação social das gerações que estavam sob a regulação destas ordenações, ora sendo apenas a receptáculo da moral misógina do período em questão.

\section{A TEMÁTICA NA HISTÓRIA DO BRASIL}

\subsection{Brasil Colônia}

A História do Brasil possui como marco fundamental a sua descoberta, no ano de 1500, pela expedição portuguesa de Pedro Álvares Cabral. Até então, os indígenas que aqui habitavam não possuíam uma estrutura jurídico-social formalizada. O equivalente ao sistema penal da época era marcado por regras consuetudinárias, bem como por um caráter místico e pelo predomínio da vingança privada, sem qualquer preocupação com proporcionalidade entre gravidade da conduta praticada e intensidade da reação imposta ao infrator (SOUZA; JAPIASSÚ, 2018, p. 30).

Aos colonizadores, a preocupação com o povoamento das novas terras não surgiu de imediato. Somente a partir do século XVII a necessidade de defender as fronteiras da terra conquistada e de interromper o indesejável processo de formação de uma população mestiça - que era considerada perigosa aos interesses da Coroa fez surgir o interesse de povoar o território (MENDES, 2017, p. 148-149). Neste contexto, mulheres brancas foram levadas de Portugal para, na Colônia, cumprirem a função de reprodutoras de uma nação branca, colaborando com a defesa do território. Percebe-se, assim, que a trajetória histórica de existência do Brasil foi, desde sempre, acompanhada por formas diversas de exercício de violência masculina em face das mulheres.

A descoberta do Brasil trouxe às novas terras, entre outras coisas, o corpo legislativo que vigia no país colonizador. Os conquistadores portugueses subjugaram os povos nativos, não inserindo qualquer influência dos costumes locais na elaboração das normas penais que passaram a viger na Colônia: o que houve, ao 
contrário, foi mera transposição do conjunto de leis vigente em Portugal (SOUZA; JAPIASSÚ, 2018, p. 30). O país estava passando por um momento de amadurecimento histórico que o fez sentir a necessidade de uma ordenação legislativa no início do século XV, motivo pelo qual surgiram as Ordenações do Reino de Portugal como resultado de um esforço pioneiro de sistematização daquilo que se caracterizou por um Direito nacional (POVEDA VELASCO, 1994, p. 14-17).

Durante o período colonial, a invasão dos holandeses na região do nordeste trouxe uma realidade jurídica diferente da que ocorria na colônia. Os colonizadores holandeses no Nordeste adaptaram a estrutura jurídico-administrativa da Holanda. O incesto e adultério eram crimes sexuais, mas que, assim como nas legislações ibéricas, se confundiam com pecado e a mulher que fosse apanhada com outro que não fosse o marido seria chicoteada em público no pelourinho.

\subsection{Brasil independente}

O Brasil se tornou independente por fatores associados ao movimento europeu e ligados aos interesses do Imperador Napoleão. A vinda da família real para o Brasil, ente 1807 e 1808, devido ao Bloqueio Continental, fez com que colonos e reinóis dividissem o mesmo espaço público e político. Essa transferência para o Brasil de grande parte da corte e os instrumentos burocráticos do Estado Português e facilitou o que viria a ser mais tarde o processo de independência do Brasil (ANGELOZZI, 2009, p. 54-55).

Em 7 de setembro de 1822, o Brasil rompeu os laços definitivos com Portugal, inaugurando um governo próprio e constituindo uma magna carta no ano de 1824 . Em 1830, Bernardo Pereira de Vasconcelos elaborou o Código Criminal brasileiro. Desde 1827 o Imperador deseja um código civil e criminal devido às necessidades jurídicas da sociedade da época, bem como em atendimento à determinação da Carta de 1824.

O Código de 1830 (BRASIL, 1831) discutia em seus 313 artigos diversos assuntos, entre eles os crimes e penas, os crimes públicos, particulares e policiais, incluindo uma discussão sobre a pena de morte no Brasil. Quanto à questão da 
mulher, o Código Criminal separava as mulheres ditas "de famílias" e as prostitutas. Segundo o Art. 222 do referido código:

Art. 222 - Ter cópula por meio de ter copula carnal por meio de violencia, ou ameaças, com qualquer mulher honesta. Penas - de prisão por tres a doze annos, e de dotar a offendida.

Se a violentada fôr prostituta. Penas - de prisão por um mez a dous anos (BRASIL, 1831, não paginado).

Neste período também se entendia a violência simbólica, com consequências psicológicas, conforme art. 223.

Art. 223. Quando houver simples offensa pessoal para fim libidinoso, causando dôr, ou algum mal corporeo a alguma mulher, sem que se verifique a copula carnal. Penas - de prisão por um a seis mezes, e de multa correspondente á metade do tempo, além das em que incorrer o réo pela ofensa (BRASIL, 1831, não paginado).

Nos casos de adultério:

Art. 250. A mulher casada, que commetter adulterio, será punida com a pena de prisão com trabalho por um a tres annos.

A mesma pena se imporá neste caso ao adultero.

Art. 251. O homem casado, que tiver concubina, teúda, e manteúda, será punido com as penas do artigo antecedente.

Art. 252. A accusação deste crime não será permittida á pessoa, que não seja marido, ou mulher; e estes mesmos não terão direito de accusar, se em algum tempo tiverem consentido no adulterio.

Art. 253. A accusação por adulterio deverá ser intentada conjunctamente contra a mulher, e o homem, com quem ella tiver commettido o crime, se fôr vivo; e um não poderá ser condemnado sem o outro (BRASIL, 1831, não paginado).

Os artigos do adultério são capazes de demonstrar sutilmente uma hierarquia sexual e sócio-comportamental da época e suas implicações na sociedade androgênica. Para a mulher adultera não há especificações de situações, ou seja, em qualquer caso haverá adultério, mesmo que esse adultério seja momentâneo e imediato. No caso do homem, este será adultero se mantiver uma outra mulher nas suas relações, o que caracteriza-se no termo teúda e manteúda, que no português arcaico significa "uma mulher mantida por alguém". 
A base de sustentação do Império foi sendo enfraquecida por elementos da segunda metade do século XIX, a exemplo da Revolução Industrial da Inglaterra e da Lei Áurea, que causaram significativas mudanças econômicas pelo mundo. Tais mudanças tiveram imediata repercussão penal, fazendo surgir a pretensão de criar leis penais adequadas aos novos tempos. O Código Penal Brasileiro entrou em vigor em 11/10/1890, dividido em 4 livros, totalizando 412 artigos.

O novo Código (BRASIL, 1890) manteve e atualizou algumas formas de categorizar mulheres, com expressões como "mulher honesta", "teúda e manteúda", "mulher pública", "prostituta". Isto denota traços de diferenciação de tratamento legal entre as mulheres: a depender de como a sociedade lia aquela mulher, ela seria objeto de maior ou menor proteção por parte da lei. Além disso, a maior parte dos crimes catalogados como de violência carnal eram descritos tendo como vítima somente as mulheres.

O Código Penal de 1890 foi objeto de severas críticas, alegadamente, por ter ignorado os avanços doutrinários que refletiram em códigos contemporâneos pelo mundo, mas não no do Brasil. Falou-se que o Código brasileiro de 1890 teria sido mera atualização da legislação penal do Império (por exemplo, teria previsto um prolongamento da estrutura prisional da época do Império). Este conjunto de críticas abalou seu prestígio e dificultou sua aplicação. Em 1891, a Câmara dos Deputados nomeou comissão para revisão do Código Penal de 1890. A reforma da legislação penal brasileira esteve em discussão pelos anos seguintes.

Enquanto não era aprovado um novo Código, de forma a remediar as dificuldades oriundas do Código anterior, o desembargador Vicente Piragibe criou uma consolidação das leis penais vigentes nos anos que se seguiram a 1890 (e que alteravam ou complementavam o referido Código). 0 trabalho do desembargador tornou-se Lei pelo Decreto no 22.213/32, e a Consolidação das Leis Penais se tornou o novo estatuto penal brasileiro, prevendo algumas poucas inovações, como o livramento condicional.

Em 07 de dezembro de 1940, houve a promulgação do Código Penal que está em vigor até os dias de hoje (BRASIL, 1940). Igualmente, parte dos crimes sexuais (à época, chamados de crimes contra os costumes) eram descritos tendo como 
vítima apenas as mulheres - a exemplo do estupro e da posse sexual mediante fraude. A especificação da mulher virgem como vítima de certos crimes se manteve neste Código, assim como a figura da mulher honesta, continuando a haver diferenciação legal na proteção das mulheres.

A partir dos anos 80, ao Direito Penal foi reservada a ingrata missão de servir de repressão política. Prisões passaram a ser lugares de suplícios, torturas e mortes dos presos políticos e daqueles a quem a Lei de Segurança Nacional considerava subversivos. Junto com isso, o país já vivia a problemática da superlotação carcerária. Tais fatores inspiraram uma reforma na Parte Geral do Código Penal, que veio a ser realizada no ano de 1984, em clima de ampla discussão teórica e democrática. No mesmo ano, entrou em vigor a Lei no 7.210 (Lei de Execuções Penais), com dispositivos consonantes com a nova Parte Geral do Código Penal. Tentou-se um anteprojeto de Parte Especial junto com tais mudanças, mas o mesmo não chegou a ser objeto de discussão no Congresso. Até a presente data, segue vigente a Parte Especial de 1940, com algumas pontuais modificações decorrentes de leis especiais.

Em 1988, a promulgação da Constituição da República Federativa do Brasil estabeleceu novos parâmetros de funcionamento para a disciplina do Direito Penal. Os princípios reguladores do controle penal consistem em princípios fundamentais de garantia do cidadão perante o poder punitivo, e estão todos amparados pelo texto constitucional de 1988 (BITENCOURT, 2017, p. 52). Entre os princípios constitucionais implícitos, ${ }^{3}$ tem-se a proporcionalidade como importante limitador para o arbítrio do sistema penal.

Como se sabe, a fórmula de talião estabelecia uma proporção entre delito e pena característica de um Direito primitivo, segundo o qual o infrator responderia pelo mal causado sofrendo-o na exata medida. Conforme a sociedade evoluiu para superar tal regramento, construiu-se um Direito Penal no qual, à multiplicidade de delitos, corresponde uma uniformidade nas formas de sancionar (CARNELUTTI, 2015, p. 30-31). Todas elas, necessariamente, tendo como base uma razoável proporção

\footnotetext{
$3 \mathrm{Em}$ contraposição aos explícitos, que se encontram textualmente determinados na redação legislativa, os princípios implícitos são aqueles que decorrem do modelo constitucional adotado, embora não estejam expressamente mencionados.
} 
entre gravidade do feito e gravidade da resposta, bem como respeitando um dos principais fundamentos da atual República Federativa do Brasil: a dignidade da pessoa humana.

\section{O COMBATE À VIOLÊNCIA CONTRA A MULHER NA SOCIEDADE MODERNA}

\subsection{0 atual Código Penal vigente}

Na Parte Geral do Código Penal, a violência contra a mulher aparece, em primeiro lugar, como agravante genérica prevista no artigo 61 , inciso II, alínea $f$. A referida norma determina como circunstância agravante o fato de o crime ter sido praticado "com violência contra a mulher na forma da lei específica" (BRASIL, 1940), fazendo referência ao conceito de violência constante na Lei no 11.340/2006 (Lei Maria da Penha). Além disso, a alínea $h$ do mesmo dispositivo estabelece como circunstância agravante o fato de o crime ter sido praticado contra mulher grávida, fazendo um recorte na proteção desta categoria específica de vítimas (as do sexo feminino).

Entende-se por circunstância do crime tudo aquilo que está em torno do fato criminoso, ou seja, tudo aquilo que o circunda. Será circunstância, portanto, toda informação concernente ao delito praticado e às pessoas nele envolvidas, desde que não se trate de elemento essencial a este crime. Os elementos sem os quais o crime inexiste não são suas circunstâncias, e sim suas elementares, conforme explicam Souza e Japiassú (2018, p. 335-336):

Para distinguir uma elementar de uma simples circunstância do crime, basta que seja feita uma eliminação hipotética. Se o crime desaparecer ou der causa a outro tipo penal, significa que se trata de uma elementar, Todavia, se não houver alteração da caracterização do crime, estar-se-á diante de uma circunstância.

As agravantes são circunstâncias que o juiz leva em consideração para, no momento da sentença condenatória, aumentar a pena na segunda fase de sua aplicação. Assim, em breve explicação, uma vez que o juiz considere o réu culpado de certo crime, fixa a sua pena base e, caso haja uma circunstância agravante que 
prepondere entre as demais, ela incidirá sobre a pena base aumentando-a, do que resulta a pena provisória.

O atual Código Penal vigente menciona a violência contra a mulher também em sua Parte Especial, composta pelos artigos 121 e seguintes, que tratam dos crimes em espécie. O artigo 121 foi alterado pela Lei no 13.104/2015, para incluir as situações em que o homicídio é considerado feminicídio (BRASIL, 2015). Esta lei criou oficialmente o termo feminicídio, o qual consiste na conduta de matar uma mulher em razão do fato de ela ser mulher. Assim, feminicídio é uma nova categoria de crime de ódio, que faz com que o agente responda pelo homicídio qualificado (artigo 121, §20, CP) - isto é, com penas cominadas maiores do que as do caput do mesmo artigo.

Por fim, em se tratando do atual Código Penal brasileiro vigente, o artigo 129 sofreu alteração pela Lei no 11.340/2006. Conhecida como Lei Maria da Penha, ela foi responsável por incluir no texto do Código Penal uma qualificadora para o crime de lesão corporal quando praticado no contexto de violência doméstica (artigo 129, $\S 90, C P)$. Embora o mencionado parágrafo não faça expressa menção à violência contra a mulher, é certo que representa avanço também na proteção desta: pode haver violência doméstica que não seja dirigida a uma mulher (NICOLITT; ABDALA; SILVA, 2018, p. 59), mas, infelizmente, não são poucas as vezes em que o ambiente familiar é cenário de crimes de violência contra as mulheres.

\subsection{Demais iniciativas recentes}

A primeira inscrição que é dada ao indivíduo, assim que nasce, é a marca de diferenciação sexual: define-se se se trata de um homem ou de uma mulher, antes mesmo que o feto complete sua evolução. Esta definição indica não apenas uma marca anatômica da pessoa, mas também seu pertencimento a um de dois grupos que, culturalmente, carregam significações imaginárias (KEHL, 2016, p. 23). Infelizmente, a História demonstra que, às mulheres, tem sido reservado o lugar de submissão, o polo passivo da sociedade, quando comparadas à classe dos homens sempre ocupantes dos cargos de poder. 
Por esta razão, a concretização da igualdade constitucional ${ }^{4}$ demanda a realização de políticas que promovam a ressignificação do papel da mulher na sociedade, permitindo que ela seja tratada, plenamente, como sujeito de direitos na exata mesma medida que o homem. Para tanto, algumas iniciativas foram criadas no sentido de promoção da mulher e de redução do seu papel de potencial vítima da violência que lhe atinge pelo simples fato de ser mulher. Tais ações, tiveram naturezas distintas - ora legislativa, ora no campo da mobilização social em favor desta categoria da população.

No ano de 2006, o Brasil deu um importante passo legislativo em matéria de proteção da mulher. Em atendimento à Constituição Federal de 1988, bem como a Convenções e tratados internacionais ratificados pela República Federativa do Brasil, entrou em vigor a Lei Maria da Penha:

A Lei $11.340 / 2006$ surgiu como importante marco nacional na luta contra a violência doméstica e familiar contra a mulher, sendo batizada de LMP em homenagem a Maria da Penha Maia Fernandes, vítima de duas tentativas de assassinato praticadas pelo seu então marido, sendo uma delas um tiro nas costas enquanto ela dormia, levando-a a paraplegia. (NICOLITT; ABDALA; SILVA, 2018, p. 63).

Em 2013, o Projeto de Lei no 292 foi apresentado pelo Senado Federal vislumbrando a modificação do tipo penal do homicídio para incluir expressamente o termo feminicídio (SOUZA, 2018, p. 139). Após manifestação da Comissão de Constituição e Justiça, o texto sofreu alterações que o deram o formato com o qual foi encaminhado à Câmara dos Deputados para revisão. O Projeto de Lei no $8305-$ A/2014 acabou sendo sancionado um dia após o Dia Internacional da Mulher, e, assim, a Lei no 13.104 foi promulgada em 09 de março de 2015, sendo chamada de Lei do Feminicídio. O feminicídio passou a ser uma das qualificadoras do homicídio (artigo $121 \mathrm{CP}$ ), sendo, ainda, incluso no rol de crimes hediondos da Lei no 8.072/1990 (Lei de Crimes Hediondos).

\footnotetext{
${ }^{4}$ A Constituição Federal de 1988 assegura o exercício da igualdade no seu preâmbulo, bem como elenca a igualdade - especificamente entre homens e mulheres - como direito e garantia fundamental do cidadão. BRASIL, Constituição da República Federativa do Brasil de 1988. Artigo 50, caput e inciso I. "Art. 50 Todos são iguais perante a lei, sem distinção de qualquer natureza, garantindo-se aos brasileiros e aos estrangeiros residentes no País a inviolabilidade do direito à vida, à liberdade, à igualdade, à segurança e à propriedade, nos termos seguintes: I - homens e mulheres são iguais em direitos e obrigações, nos termos desta Constituição;(...)"
} 
Junto com tais iniciativas legislativas, a popularização da Internet e das redes sociais permitiu a propagação de uma consciência coletiva acerca da violência contra a mulher. Movimentos como "Me too"5, "Meu professor ensinou"6, "Mas ele nunca me bateu"7, "Project unbreakable"8, entre outros, foram responsáveis por difundir conhecimento acerca do que é violência contra a mulher, e do quão grave é este problema para toda a sociedade. Além de compartilhar com os homens a questão que vitima tão severamente as mulheres, campanhas como estas trouxeram para as próprias mulheres a noção de que já foram vítimas de formas diversas de violência, em situações costumeiramente naturalizadas. Reconhecer-se como vítima é o primeiro passo para combater o agressor, e estas iniciativas têm exercido papel fundamental para disseminar informação e conhecimento a este respeito.

\section{CONSIDERAÇÕES FINAIS}

Não é possível pensar que a solução de um problema social passe meramente pela criação de leis. Se é certo que o Direito precisa sempre tentar acompanhar as modificações e evoluções da sociedade a que rege, é também razoável concluir que não se trata do único instrumento de combate das diversas mazelas que afligem a população. Quando se trata da violência contra a mulher, suas raízes históricas e culturais a tornam um problema de extrema complexidade, e o caminho para solucioná-la não é tão simples.

"O combate à cultura da intolerância requer o fortalecimento da cultura do respeito às diversidades" (SOUZA, 2018, p. 16) e, para tanto, não basta colocar em

\footnotetext{
${ }^{5}$ Movimento das mulheres da classe artística de todo o mundo. A proposta é para que cada mulher que já sofreu assédio ou abuso sexual escreva "me too" (expressão em inglês que significa "eu também") em algum status de rede social, demonstrando às demais vítimas que elas não estão sozinhas.

${ }^{6}$ Campanha realizada pelas mulheres da Faculdade de Direito da UERJ em repúdio ao machismo dos seus professores em sala de aula. O movimento acabou abrindo espaço para que alunas de outros cursos e faculdades tornassem públicas situações de assédio praticadas por professores contra elas em sala de aula.

7 Movimento de redes sociais que reúne e publica relatos de violências diversas, além da física, de forma a conscientizar as mulheres sobre o fato de que elas podem estar em uma relação abusiva, mesmo que não tenham sido fisicamente agredidas.

8 Projeto fotográfico (em português, significa "projeto inquebrável") exposto em redes sociais. Nas fotografias, as vítimas de violência sexual, violência doméstica e abuso infantil seguram um pedaço de papel/cartolina com os dizeres do agressor no contexto da prática da violência.
} 
vigor um texto legislativo. Mudanças culturais demandam tempo, demandam iniciativas em matéria de educação, demandam, fundamentalmente, uma mudança no consciente coletivo da população. O Direito vigente precisa fazer sua parte em assegurar que as mulheres sejam objeto de proteção legal, mas o real enfrentamento desta questão passa necessariamente pela consciência de que somos todos igualmente dignos de direitos e garantias em sociedade.

\section{REFERÊNCIAS}

ANGELOZZI, Gilberto Aparecido. História do Direito no Brasil. Rio de Janeiro: Maria Augusta Delgado, 2009.

ARISTÓTELES. A Política. São Paulo: Martin Claret, 2006.

BITENCOURT, Cezar Roberto. Tratado de direito penal: parte geral 1. 23. ed. rev. ampl. e atual. São Paulo: Saraiva, 2017.

BRASIL. Decreto-Lei no 2.848, de 07 de dezembro de 1940. Código Penal. Rio de Janeiro: Presidência da República, 1940. Disponível em:

http://www.planalto.gov.br/ccivil_03/decreto-lei/del2848.htm. Acesso em: 20 dez. 2018.

BRASIL. Decreto no 847, de 11 de outubro de 1890. Promulga o Código Penal. [Rio de Janeiro: Sala das sessões de Governo Provisório], 1890. Disponível em: http://www.planalto.gov.br/ccivil_03/decreto/1851-1899/D847.htm. Acesso em: 17 dez. 2018.

BRASIL. Lei de 16 de dezembro de 1830. Manda executar Código Criminal. [Rio de Janeiro]: Secretaria de Estado dos Negócios da Justiça, 1831. Disponível em: http://www.planalto.gov.br/ccivil_03/leis/lim/LIM-16-12-1830.htm. Acesso em: 18 dezembro de 2018.

BRASIL. Lei no 13.104, de 9 de março de 2015. Altera o art. 121 do Decreto-Lei n० 2.848, de 7 de dezembro de 1940 - Código Penal, para prever o feminicídio como circunstância qualificadora do crime de homicídio, e o art. $1^{0}$ da Lei no 8.072, de 25 de julho de 1990, para incluir o feminicídio no rol dos crimes hediondos. Brasília, DF: Presidências da República, 2015. Disponível em:

http://www.planalto.gov.br/ccivil_03/_ato2015-2018/2015/lei/l13104.htm. Acesso em: 20 dezembro de 2018.

CANELA, Cristina Kelly. O "stuprum per vim" no direito romano. 2009. 171f. Tese (Doutorado em Direito Privado) - Universidade de São Paulo, 2009. 
CARNELUTTI, Francesco. 0 problema da pena. Tradução: Ricardo Pérez Banega. São Paulo: Pillares, 2015.

CASTRO, Flávia Lages. História do Direito, Geral e Brasil. 5. ed. Rio de Janeiro: Lumen Juris, 2007.

JESUS JR., Guilhardes. A condição da mulher no Império Romano: noções jurídicas e sociais. In: Encontro Nacional de produção científica do grupo institucional de pesquisa em direitos humanos e fundamentais, 2., 2011, Ilhéus. Anais [...]. Ilhéus, BA: Universidade Estadual de Santa Cruz, 2011. Disponível em:

http://www.redireito.org/wp-content/uploads/2013/05/3-A-

CONDI+\%C3\%A7+\%C3\%A2O-DA-MULHER-NO-IMP+\%C3\%ABRIO-ROMANOfalta-aparte-de-Camila.pdf. Acesso em: 12 mar. 2018.

KEHL, Maria Rita. Deslocamentos do feminino: a mulher freudiana na passagem para a modernidade. 2. ed. São Paulo: Boitempo, 2016.

LORRIS, Guillaume de; MEUNG Jean de. Le roman de la rose: Tome I. Paris: [s.n.], 1878. Disponível em: https://www.gutenberg.org/files/16816/16816-pdf.pdf. Acesso em: abril de 2018.

MENDES, Soraia da Rosa. Criminologia feminista: novos paradigmas. 2. ed. São Paulo: Saraiva, 2017.

NICOLITT, André; ABDALA, Mayara Nicolitt; SILVA, Laís Damasceno. Violência doméstica: estudos e comentários à Lei Maria da Penha. Belo Horizonte: D’Plácido, 2018.

PIERANGeLLI, J. H. Códigos Penais do Brasil: evolução histórica. Bauru, SP: Jalovi, 1980.

POVEDA VELASCO, Ignacio Maria. Ordenações do Reino de Portugal. Revista da Faculdade de Direito, São Paulo, v. 89, p. 11-67, jan./dez. 1994.

SOUZA, Artur de Brito Gueiros; JAPIASSÚ, Carlos Eduardo Adriano. Direito penal: volume único. São Paulo: Atlas, 2018.

SOUZA, Regina Cirino Alves Ferreira de. Crimes de ódio: racismo, feminicídio e homofobia. Belo Horizonte: D’Plácido, 2018.

TÔRRES, Moisés Romanazzi. Considerações sobre a condição da mulher na Grécia Clássica (sécs. V e IV a.C.). In: COSTA, Ricardo (org.). Mirabilia 1. [S.I.:s.n.], 2001. Disponível em https://dialnet.unirioja.es/descarga/articulo/2226874.pdf. Acesso em: 12 mar. 2018. 
UNIVERSIDADE DE COIMBRA. As Ordenações Filipinas. [Coimbra: s.n.],[1998]. Livro V. Disponível em: http://www1.ci.uc.pt/ihti/proj/filipinas/ordenacoes.htm. Acesso em: 10 set. 2017. 